\title{
Influence of High Volume Fly Ash and Recycled Aggregates in Chloride and Carbonation Resistance of Concrete
}

\author{
Miren Etxeberria and Fernando Álvarez
}

\author{
Departament of Civil and Environmental Engineering, Universitat Politècnica de Catalunya- \\ BarcelonaTECH, Campus Nord UPC, 08034-Barcelona, Spain, miren.etxeberria@upc.edu
}

\begin{abstract}
This paper deals with the evaluation of the influence of recycled concrete aggregate (RCA) and the employment of high volume of fly ash (FA) on the physical, mechanical and durability (chloride ion penetration and carbonation) properties of concretes. The obtained values of which, being compared to those of conventional concretes. Concrete was produced using $0 \%, 25 \%$ and $50 \%$ FA in replacement of Portland cement, and $0 \%$ and $50 \%$ of RCA in substitution of natural aggregates. All the concretes were produced employing an effective water-cement ratio of 0.50. The physical properties at 28 days and the compressive strength at 7,28 and 90 days were determined in all the concretes produced as well as the assessment of durability (penetration of chlorides and depth of carbonation) on all concrete mixtures. The depth of the carbonation was determined after submitting every concrete sample to a series of accelerated tests at $20 \%$ of $\mathrm{CO}_{2}$ concentration during 7, 14 and 28 days after the curing period in the humidity room and pre-condition in the laboratory. The chloride penetration was determined at 28 and 90 days of curing. It was concluded that the employment of 50\% of un-carbonated RCA increased the early strength of concrete produced using FA, and at late ages, RCA concretes achieved similar strength when $25 \%$ of FA was employed. The concrete produced with $50 \%$ of FA achieved the highest resistance to chloride ion penetration also when RCA was employed. Although the use of FA increased the carbonation depth of the concrete samples, the employment of the un-carbonated RCA reduced that effect. The employment of RCA with CEM II or binder with 25\% of FA caused the lowest carbonation depth.
\end{abstract}

Keywords: Fly Ash, Recycled Aggregates, Concrete, Carbonation, Chloride Resistance.

\section{Introduction}

Concrete production has a high impact on our environment due to the abundant consumption of energy and a large amount of $\mathrm{CO}_{2}$ emissions in cement production. In addition, the demolition of concrete structures causes a considerable volume of waste to end up in landfills. These problems may be reduced, achieving a green concrete, by employing fly ash (FA) as supplementary cementitious materials and recycled concrete aggregates (RCA) in replacement of cement and natural aggregates, respectively for concrete production (Marinković, Dragaš, Ignjatović, and Tošić, 2017).

It is known that the RCA is suitable for concrete production (Chen et al., 2019), in addition the employment of recycled aggregate concrete (RAC) as structural material has been widely analysed and validated for many applications (Pedro, De Brito, and Evangelista, 2014). However, the durability of concrete produced with RCA is actively being studied in order to improve its qualities (Guo et al., 2018). According to Guo et al. (Guo et al., 2018) RAC has lower chloride ion diffusion resistance than conventional concretes due to the RCA's high porosity. According to the results of a carbonation resistance test, when the RAC were produced employing at least $70 \%$ of RCA, the resistance was found to be higher due to the larger amount of mortar in recycled concrete. In contrast, the results of studies by Silva et al. (Silva et al., 
2015) determined that the carbonation of concrete produced with $100 \%$ of RCA was 2.5 times higher than that produced with natural aggregates.

On the other hand, today the use of FA up to $15-20 \%$ (Chandra and Bendapudi, 2015) or up to $15-30 \%$ (Xu and Shi, 2018) in concrete production is considered usual and it has been determined that the employment of high amount of FA controlled the temperature of concrete and achieved adequate mechanical and durability properties. It is known that the concretes produced with FA have low strength at initial ages, this effect being more evident when higher percentages of FA are employed in concrete production and less evident when concrete are produced with a low water/cement ratio. However at later ages, the strength of concrete increases due to the reaction of its FA with Portlandite (Kocak and Nas, 2014; Xu and Shi, 2018). According to Lam et al. (L. Lam, Y.L. Wong, 1998) the chloride ion penetration resistance of concrete is higher when FA is employed. Dinakar et al. (Dinakar, Kartik Reddy, and Sharma, 2013) described that concretes achieve their highest strength and chloride ion resistance when up to $30 \%$ of FA is employed for concrete production. However, several other researchers (Kurda, De Brito, and Silvestre, 2019) determined that concrete produced with FA achieves lower carbonation resistance than the concrete produced employing 100\% of Portland cement.

In this paper, the influence of RCA and the employment of high volumes of FA on the physical, mechanical and durability (chloride ion penetration and carbonation) properties of concretes have been evaluated, and those values were compared to those of conventional concretes. Concretes

cement, and $0 \%$ and

2 Materials

2.1 Binder
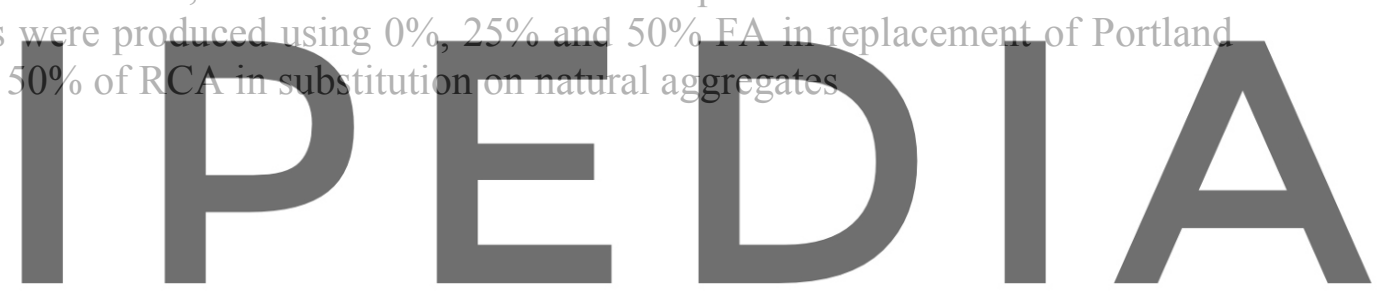

The cement types of CEM II A-L 42.5R (with 12\% limestone, named CEMII) and CEM I 52.5R

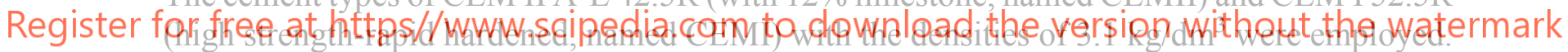

Class F fly ash (FA) with a density of $2.16 \mathrm{~kg} / \mathrm{dm}^{3}$ was also employed.

\subsection{Aggregates}

Three fractions of natural limestone aggregates were used for concrete production: fine (NS of $0 / 4 \mathrm{~mm}$,) and coarse aggregates (CA1 of $5 / 10 \mathrm{~mm}$ and CA2 of $8 / 20 \mathrm{~mm}$ ). The dry density of NS, CA1 and CA2 were $2.58 \mathrm{~kg} / \mathrm{dm}^{3}, 2.67 \mathrm{~kg} / \mathrm{dm}^{3}$ and $2.67 \mathrm{~kg} / \mathrm{dm}^{3}$, respectively. The absorption capacity was of $1.79 \%, 0.75 \%$ and $0.57 \%$, respectively.

The recycled concrete aggregate (RCA) was produced via the crushing of a parent concrete, namely one-year-old waste, $30 \mathrm{MPa}$ concrete specimens from a concrete company. The component of the parent concrete being CEM II A-L 42.5R cement and limestone aggregates. The RCA was used for concrete production immediately after the parent concrete was crushed, and the RCA aggregates were un-carbonated. The grading distribution was defined by the fraction $5 / 20 \mathrm{~mm}$. Its density was of $2.33 \mathrm{~kg} / \mathrm{dm}^{3}$ and an absorption capacity of $5.35 \%$.

\section{Mix Design and Production Process}

Two stages of concrete productions were carried out. In stage 1, all the concretes were produced 
employing $100 \%$ of natural aggregates. Four different concretes were produced in which different binders were employed. CC, 100\% of CEMII; CFA25, 25\% (in weight) of CEMII was replaced by FA; CFA50: 50\% of CEMII was replaced by FA and CFA50.2: 50\% of binder was CEMI and $50 \%$ of FA (see Table 1). In stage 2, all the mixtures were produced employing $50 \%$ of the aggregates volume defined in the CC mixtures replaced by RCA. Four different concrete mixtures were produced: CRA, $100 \%$ of CEMII; CRAFA25, 25\% (in weight) of CEMII was replaced by FA; CRAFA50, 50\% of CEMII was replaced by FA and CRAFA50.2, 50\% of binder was CEMI and $50 \%$ of FA (see table 1).

The effective w/c ratio of 0.50 was maintained constant in all concretes. In stage 1 , in order to determine the effective $\mathrm{w} / \mathrm{c}$ ratio, the effective absorption capacity of $90 \%, 50 \%$ and $50 \%$ of the total absorption capacity of NS, CA1 and CA2, respectively were determined. In addition, in stage 2, the effective absorption capacity of RCA was determined as being $80 \%$ of its total absorption capacity. The RCA was used with high humidity, having $75-80 \%$ of water absorption capacity, and their moisture content was measured prior to their use.

The concrete specimens were produced and cured following UNE EN 12390-2:2001 regulations and were manually compacted using a steel rod. The concrete specimens were then covered with a plastic sheet and air-cured for the first $24 \mathrm{~h}$. After $24 \mathrm{~h}$ of casting, the specimens were demoulded and then stored in a humidity room and kept at $21^{\mathrm{a}} \mathrm{C}$ and $95 \%$ of humidity until the test ages were reached for the physical, mechanical and chloride ion penetration test. The specimens taken from the humidity room after 28 days for carbonation resistance testing were sent to the laboratery to underoe pre-conditioning for 14 days at $400 \mathrm{ppm}, 24^{\circ} \mathrm{C}$ and $550 \%$ humidity before being $\mathrm{p}$

A superplasticizer bas $0.50 \%$ with respect to cement a slump test of $17-19 \mathrm{~cm}$. T determined. Table 1 sho its capacity to densify the cement paste, in contrast the employment of RCA decreased the

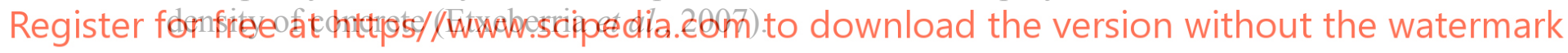

Table 1. Mix proportions of Stage 1 and Stage 2 concrete mixtures. The values are given of $\mathrm{kg}$ of component $/ \mathrm{m}^{3}$ of concrete production (W: water, Ad: admixture, Effect: Effective).

\begin{tabular}{ccccccccccc}
\hline & CEM & FA & $\begin{array}{c}\text { W } \\
\text { Total }\end{array}$ & NS & CA1 & CA2 & RCA & $\begin{array}{c}\text { Ad. } \\
(\%)\end{array}$ & $\begin{array}{c}\text { Effect. } \\
\text { w/c }\end{array}$ & $\begin{array}{c}\text { Density } \\
\mathbf{( k g / d m}^{3}\end{array}$ \\
\hline CC & 350 & & 192.5 & 900 & 275.2 & 647 & 0 & 0.50 & 0.5 & 2.24 \\
\hline CFA25 & 262.5 & 87.5 & 192.5 & 867.9 & 275.2 & 647 & 0 & 0.50 & 0.5 & 2.34 \\
\hline CFA50 & 175 & 175 & 192.5 & 835.9 & 275.2 & 647 & 0 & 0.50 & 0.5 & 2.36 \\
\hline CFA50.2 & 175 & 175 & 192.5 & 835.9 & 275.2 & 647 & 0 & 0.50 & 0.5 & 2.36 \\
\hline \multicolumn{8}{c}{ STAGE 2 } \\
\hline CRA & 350 & & 213.4 & 900 & 137.6 & 323.5 & 400 & 0.50 & 0.5 & 2.31 \\
\hline CRAFA25 & 262.5 & 87.5 & 213.4 & 867.9 & 137.6 & 323.5 & 400 & 0.50 & 0.5 & 2.30 \\
\hline CRAFA50 & 175 & 175 & 213.5 & 835.9 & 137.6 & 323.5 & 400 & 0.50 & 0.5 & 2.31 \\
\hline CRAFA50.2 & 175 & 175 & 213.5 & 835.9 & 137.6 & 323.5 & 400 & 0.50 & 0.5 & 2.33 \\
\hline
\end{tabular}




\section{Test Procedure}

\subsection{Physical and Compressive Strength}

Physical properties were measured according to ASTM C 642 "Standard Test Method for Density, Absorption and Voids in Hardened Concrete" at 28 days after casting. Three cubic specimens were used in this test for each concrete mixture produced.

The compressive strength of concretes at 7,28 and 90 days were determined following UNEEN 12390-3:2009 specifications. Three cylindrical specimens were used for each concrete mixtures.

\subsection{Carbonation and Chloride Resistance}

The concretes were submitted to accelerated carbonation test, following GB T50082-2009 standards, in order to assess the carbonation penetration resistance of each concrete produced employing different types of binders as well as the RCA. The concrete specimens were placed in a $\mathrm{CO}_{2}$ chamber at $20 \% \mathrm{CO}_{2}, 20^{\circ} \mathrm{C}$ and $60 \%$ of $\mathrm{RH}$ for 7,14 and 28 days after their curing process of 28 days and pre-conditioning period of 2 weeks. The concentration of the $\mathrm{CO}_{2}$ employed was very high. It is known that the carbonation coefficient increases with an increase in carbon dioxide concentration (Shah and Bishnoi, 2018). In addition, at long test periods, the high concentrations of $\mathrm{CO}_{2}$ cause a change of the cement paste microstructure compared to that of samples placed in natural exposure (Castellote et al., 2009). However, the high concentration of $\mathrm{CO}_{2}$ conditions, in short periods of testing, allow the concrete's resistance to carbonation to
be characterized (Hyvert et al., 2010). Two specimens of each concrete were employed for
carbonation depth nueasurement. The compressive strength of each concrete was also
determined.
The chloride penetrability of concrete was determined following the ASTM C1202 1997) standard. The chloride ion penetration resistance of concrete is represented by the total charge

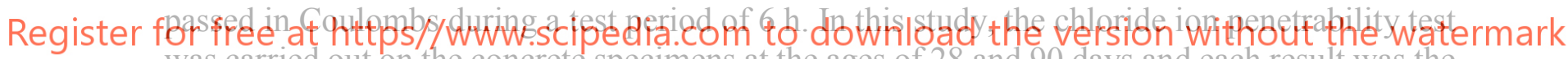
was carried out on the concrete specimens at the ages of 28 and 90 days and each result was the average of two measurements.

\section{Results}

\subsection{Physical and Compressive Strength}

Table 2 shows the physical properties obtained by all the concretes analysed. The employment of FA increased the density and decreased the absorption capacity of concrete due to its reaction with $\mathrm{Ca}(\mathrm{OH})_{2}$ (Deschner et al., 2012). The CFA50.2 produced with $50 \%$ of FA in substitution of CEMI achieved the lowest absorption capacity. The employment of RCA, in stage 2, decreased the density of its Stage 1 corresponding concrete. The CRA achieved $18 \%$ higher absorption capacity than that of CC concrete. Similar results were obtained by Kurda et al. (Kurda, de Brito, and Silvestre, 2019). The absorption capacity of recycled aggregate concrete was lower when FA was employed in its production. The CRAFA50.2, produced with CEMI, achieved the lowest absorption capacity. CRAFA50 and CRAFA50.2 achieved a higher density, lower absorption and porosity than that of the $\mathrm{CC}$ concrete.

Table 2 also shows the compressive strength at 7 days, 28 days and 90 days of all the 
concretes produced. The CC mixture achieved the highest compressive strength at 7, 28 and 90 days. In addition, the concretes produced employing $25 \%$ of FA achieved the strength of CC concrete. Similar results were obtained by Nath and Sarker (2011) at 28 and 90 days. The concretes produced with $50 \%$ of FA achieved lower strength than the CC concrete in all the tested ages. Although the employment of CEMI improved the properties achieved by concrete produced using CEMII, the CFA50.2 proved to have $14.8 \%$ lower strength than that of CC after 90 days (see figure 1). This in all probability was due to a none reaction in some of its high volume of FA (Hemalatha and Ramaswamy, 2017; Xu and Shi, 2018). In stage 2, the concrete CRA achieved the highest strength at 7 and 28 days, and the CRAFA25 concrete after 90 days.

Table 2. Physical properties of concretes produced in Stage 1 and 2, Compressive strength of concretes at 7, 28 and 90 days.

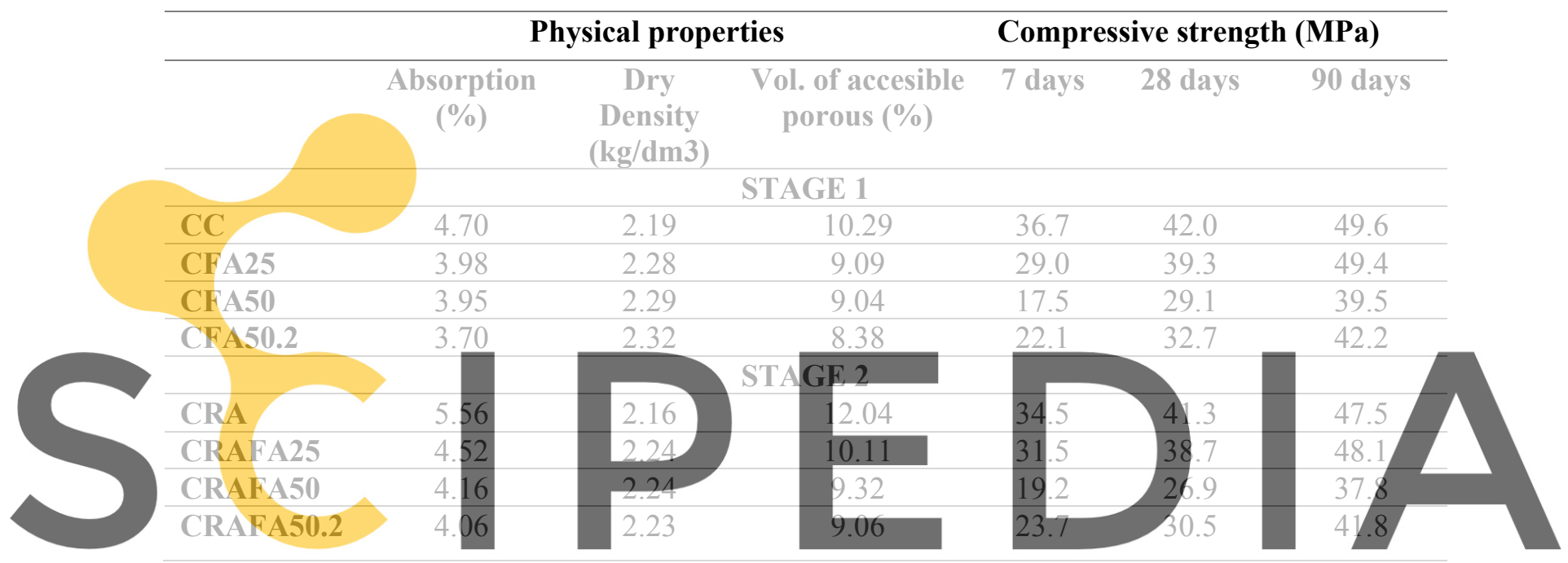

Register for free at https//WWWW.Scipedia.compto downłoad the version without the watermark

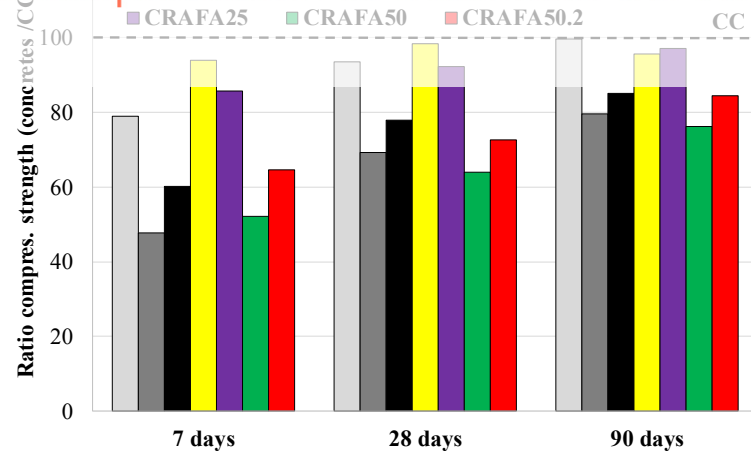

Figure 1. Ratio of the compressive strength of all the concrete with respect to that of CC concrete.

At 7 days of curing, the concretes produced employing RCA and FA achieved a higher strength than that of the concretes produced employing FA and NA (see Figure 1). The rough surface and attached un-carbonated mortar of the RCA caused adequate ITZ in CRA (Etxeberria et al., 2007).

At 28 days and 90 days, the concrete produced with RCA achieved a slightly lower strength 
to the concretes produced employing natural aggregates. In stage 2, the CRAFA25 achieved the highest strength at 90 days due to the pozzolanic effect of FA and its reaction with $\mathrm{Ca}(\mathrm{OH}) 2$, similar behaviour was determined by Kou and Poon (2013).

In addition, the two concretes produced employing $25 \%$ of FA achieved the strength of the $\mathrm{CC}$ concrete. Cement type I 52.5R (CEMI) was required for concrete employing 50\% of FA in order to avoid a high strength reduction at 90 days.

\subsection{Carbonation and Chloride Resistance}

Figure $2 \mathrm{a}$ shows the chloride penetration resistance of each concrete at 28 and 90 days, in accordance with the total charge passed value obtained, which are categorized as low, moderate and high corrosion risk.

At 28 days, almost all of the concretes were classified with moderate risk for corrosion, except the CC and CRA concretes, which were classified as high risk of corrosion. The employment of a higher percentage of FA reduced the corrosion risk. The concretes produced employing 50\% of FA and RCA (CRAFA50 and CRAFA50.2) achieved the lowest value of the total charge passed. At 90 days, the concretes produced with 50\% of FA, CFA50.2 and CRAFA50.2, achieved the lowest value. The CRA concrete was found to still have a high risk of corrosion after 90 days of curing.

In stage 1, the concretes produced with 50\% FA and natural aggregates achieved the highest decrease of the total charge passed value from 28 days to 90 days. The reduction of the total charge passed of the CFA50.2, CFA5Q, CFA25 and CC concretes were 53\%, 40\%, 25\% and $19 \%$ respectively. In CRA were $27 \%, 10 \%$, on the chloride resistanc The average carbonation depth of each concre $\mathrm{CO}_{2}$ during 7 days,
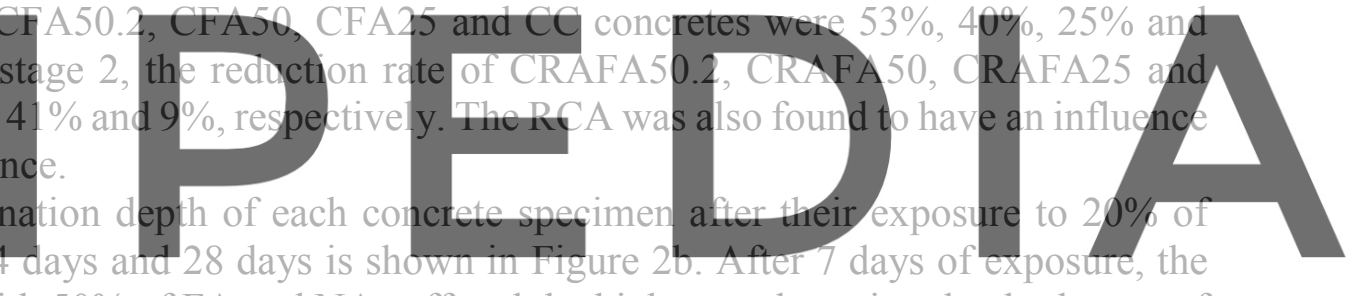

concretes produced with $50 \%$ of FA and NA suffered the highest carbonation depth, the use of

Register forofreerat Attedsd dWWWA.scipeddiareian to download the version without the watermark

It is clear that the employment of FA increased the depth of carbonation within the concrete samples. Several researchers have also determined this (Khunthongkeaw, Tangtermsirikul, and Leelawat 2006; Kurda, De Brito, et al., 2019). The concretes produced with 100\% of CEMII as well as employing $25 \%$ of FA achieved the highest resistance to carbonation at any time, being higher when RCA was employed for concrete production. In this research work un-carbonated RCA aggregate was employed, which was carbonated during their contact with $\mathrm{CO}_{2}$, increasing the concretes carbonation resistance. Similar results were obtained by Thomas et al. (Thomas et al., 2013). Most of the research work carried out up to date define that concrete produced employing RCA achieved lower carbonation resistance due to its high porosity of RCA (Kurda, De Brito, et al., 2019; Leemann and Loser 2019), however the carbonated or un-carbonated state of RCA could modify this behaviour. After 28 days of $\mathrm{CO}_{2}$ exposure, the concretes produced with $50 \%$ of RCA and $50 \%$ of FA suffered a greater carbonation process. In all probability, the result was due to a higher presence of cement paste which became modified as a result of a high $\mathrm{CO}_{2}$ concentration (Castellote et al., 2009). However, this effect will be lower at natural exposure. 

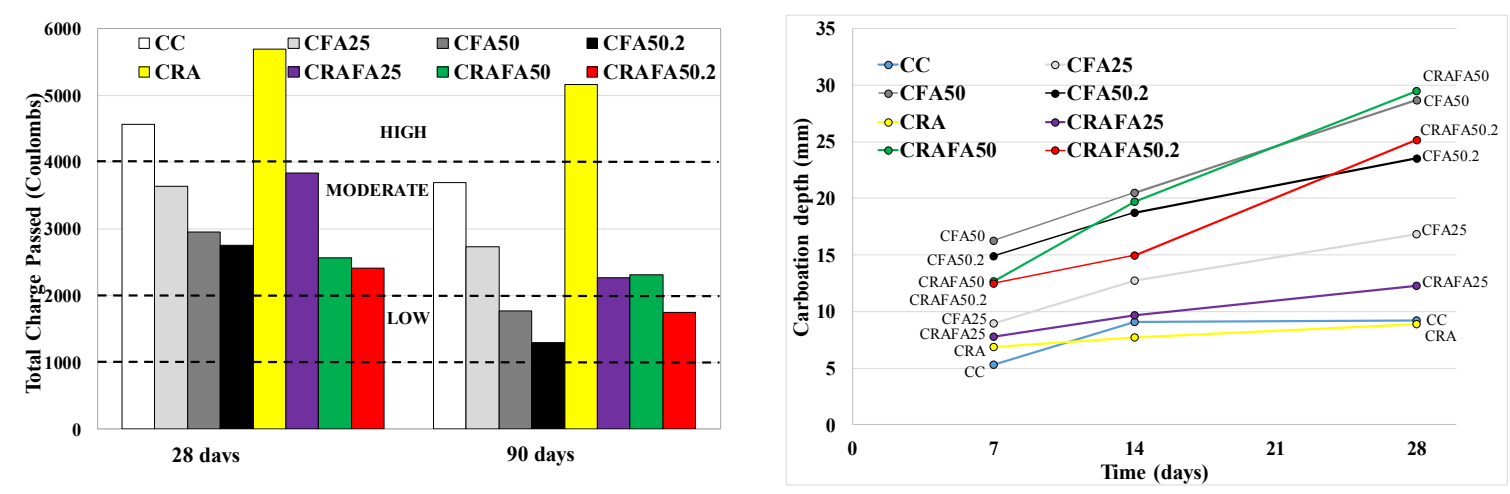

Figure 2 a) Chloride-ion penetration of concrete mixtures and ASTM corrosion ranges. b) carbonation depth of concrete mixtures.

\section{Conclusions}

The following conclusions can be drawn based on the results presented above:

The effect of RCA in decreasing and increasing the density and absorption capacity, respectively, of concretes was lessened by employing FA. The CRAFA50 and CRAFA50.2 achieved a higher density, lower density and porosity than that of the CC concrete.

- The results of compressive strength test at 7 days determined that the concretes produced employing FA achieved higher strength when RCA was used than the concretes produced with NA. At 28 and 90 days. The concrete produced with 50\% of RCA with or without employing $25 \%$ of FA achieved similar strength to that of the CC conqrete. At 90 days, th produced with CEM I and $50 \% \mathrm{FA}$ achieyed $14 \%$

Chloride ion penetrat

of aggregates used. The

chloride ion penetration. The con

produced with

corrosion when $25 \%$ or $50 \%$ of FA was employed for concrete production. CRA (the concrete



The employment of FA increased the depth of the carbonation of the concrete samples. After

7 days of $20 \% \mathrm{CO}_{2}$ exposure, the use of RCA was shown to reduce the carbonation depth of the concretes produced with 50\% FA and NA. The employment of RCA in concrete production with CEM II or employing $25 \%$ of FA caused the lowest carbonation depth.

\section{ORCID}

Miren Etxeberria: https://orcid.org/0000-0003-2208-6207

\section{References}

Castellote, M., Fernandez, L., Andrade, C., and Alonso, C. (2009). Chemical changes and phase analysis of OPC pastes carbonated at different CO2 concentrations. Materials and Structures/Materiaux et Constructions, 42(4), 515-525. https://doi.org/10.1617/s11527-008-9399-1

Chandra, S., and Bendapudi, K. (2015). Contribution of Fly ash to the properties of Mortar and Concreteb h,u h I,... International Journal of Earth Sciences and Engineering, 04(October 2011), 1017-1023.

Chen, W., Jin, R., Xu, Y., Wanatowski, D., Li, B., Yan, L., and Yang, Y. (2019). Adopting recycled aggregates as sustainable construction materials: A review of the scientific literature. Construction and Building Materials, 218, 483-496. https://doi.org/10.1016/j.conbuildmat.2019.05.130

Deschner, F., Winnefeld, F., Lothenbach, B., Seufert, S., Schwesig, P., Dittrich, S., and Neubauer, J. (2012). 
Hydration of Portland cement with high replacement by siliceous fly ash. Cement and Concrete Research, 42(10), 1389-1400. https://doi.org/10.1016/j.cemconres.2012.06.009

Dinakar, P., Kartik Reddy, M., and Sharma, M. (2013). Behaviour of self compacting concrete using Portland pozzolana cement with different levels of fly ash. Materials and Design, 46, 609-616. https://doi.org/10.1016/j.matdes.2012.11.015

Etxeberria, M., Vázquez, E., Marí, A., and Barra, M. (2007). Influence of amount of recycled coarse aggregates and production process on properties of recycled aggregate concrete. Cement and Concrete Research, 37(5), 735-742. https://doi.org/10.1016/j.cemconres.2007.02.002

Guo, H., Shi, C., Guan, X., Zhu, J., Ding, Y., Ling, T. C., and Wang, Y. (2018). Durability of recycled aggregate concrete - A review. Cement and Concrete Composites, 89, 251-259. https://doi.org/10.1016/j.cemconcomp.2018.03.008

Hemalatha, T., and Ramaswamy, A. (2017). A review on fly ash characteristics - Towards promoting high volume utilization in developing sustainable concrete. Journal of Cleaner Production, 147, 546-559. https://doi.org/10.1016/j.jclepro.2017.01.114

Hyvert, N., Sellier, A., Duprat, F., Rougeau, P., and Francisco, P. (2010). Dependency of C-S-H carbonation rate on $\mathrm{CO} 2$ pressure to explain transition from accelerated tests to natural carbonation. Cement and Concrete Research, 40(11), 1582-1589. https://doi.org/10.1016/j.cemconres.2010.06.010

Khunthongkeaw, J., Tangtermsirikul, S., and Leelawat, T. (2006). A study on carbonation depth prediction for fly ash concrete. Construction and Building Materials, 20(9), 744-753. https://doi.org/10.1016/j.conbuildmat.2005.01.052

Kocak, Y., and Nas, S. (2014). The effect of using fly ash on the strength and hydration characteristics of blended cements. Construction and Building Materials, 73, 25-32. https://doi.org/10.1016/j.conbuildmat.2014.09.048

Kou, S. C., and Poon, C. S. (2013). Long-term mechanical and durability properties of recycled aggregate concrete prepared with the incorporation of fly ash. Cement and Concrete Composites, 37(1), 12-19. https://doi.org/10.1016/j.c/o,

Kurda, R., de Brito, J., and recycled concrete https://doi.org/10.1016/j.c

Kurda, R., De Brito, J., and Silvestre, J recycled concrete aggreg https://doi.org/10.1016/j.jcou.2018.11.004
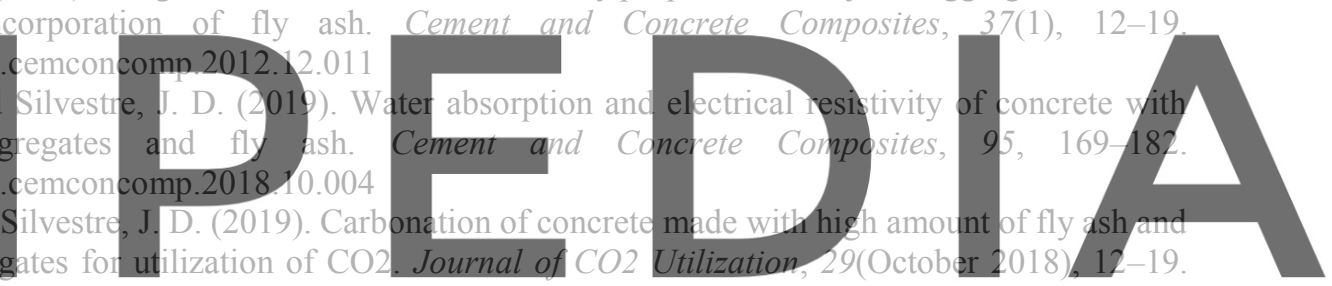

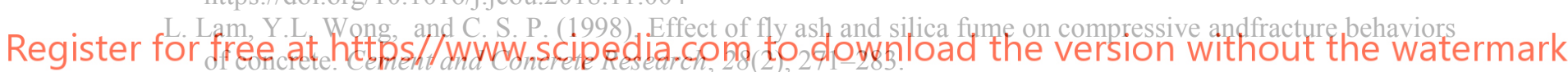

Leemann, A., and Loser, R. (2019). Carbonation resistance of recycled aggregate concrete. Construction and Building Materials, 204, 335-341. https://doi.org/10.1016/j.conbuildmat.2019.01.162

Marinković, S., Dragaš, J., Ignjatović, I., and Tošić, N. (2017). Environmental assessment of green concretes for structural use. Journal of Cleaner Production, 154, 633-649. https://doi.org/10.1016/j.jclepro.2017.04.015

Nath, P., and Sarker, P. (2011). Effect of fly ash on the durability properties of high strength concrete. Procedia Engineering, 14, 1149-1156. https://doi.org/10.1016/j.proeng.2011.07.144

Pedro, D., De Brito, J., and Evangelista, L. (2014). Influence of the use of recycled concrete aggregates from different sources on structural concrete. Construction and Building Materials, 71, 141-151. https://doi.org/10.1016/j.conbuildmat.2014.08.030

Shah, V., and Bishnoi, S. (2018). Carbonation resistance of cements containing supplementary cementitious materials and its relation to various parameters of concrete. Construction and Building Materials, 178, 219232. https://doi.org/10.1016/j.conbuildmat.2018.05.162

Silva, R. V., Neves, R., De Brito, J., and Dhir, R. K. (2015). Carbonation behaviour of recycled aggregate concrete. Cement and Concrete Composites, 62, 22-32.https://doi.org/10.1016/j.cemconcomp.2015.04.017

Thomas, C., Setién, J., Polanco, J. A., Alaejos, P., and Sánchez De Juan, M. (2013). Durability of recycled aggregate concrete. Construction and Building Materials, 40, 1054-1065. https://doi.org/10.1016/j.conbuildmat.2012.11.106

$\mathrm{Xu}, \mathrm{G}$., and Shi, X. (2018). Characteristics and applications of fly ash as a sustainable construction material: A state-of-the-art review. Resources, Conservation and Recycling, 136(August 2017), 95-109. https://doi.org/10.1016/j.resconrec.2018.04.010 